\title{
PERBANDINGAN KINERJA TELLER KRIYA DAN TELLER ORGANIK PT. BANK SYARIAH MANDIRI
}

\section{COMPARISON OF KRIYA AND ORGANIC TELLER PERFORMANCE PT. BANK MANDIRI SYARIAH}

\author{
Mila Nurmala Dewi1a, Adi Rahmannur Ibnu' ${ }^{2}$, Muhamad Komarudin ${ }^{3}$ \\ 1Program Studi Perbankan Syariah Fakultas Ekonomi Islam Universitas Djuanda, Jl Tol Ciawi \\ Nomor 1 Kota Pos 35 Bogor 16720 \\ 2Program Studi Perbankan Syariah Fakultas Ekonomi Islam Universitas Djuanda, Jl Tol Ciawi \\ Nomor 1 Kota Pos 35 Bogor 16720 \\ ${ }^{3}$ Program Studi Perbankan Syariah Fakultas Ekonomi Islam Universitas Djuanda, Jl Tol Ciawi \\ Nomor 1 Kota Pos 35 Bogor 16720 \\ aKorespondensi: Mila Nurmala Dewi, e-mail: mila.nurmila@unida.ac.id
}

\begin{abstract}
This study aims to examine the differences in the performance of kriya tellers (contract employees) and organic tellers (permanent employees) of PT Bank Syariah Mandiri. This research is a comparative study using quantitative methods. Data management using Mann Whitney. The object this research is PT Bank Syariah Mandiri. The sample in this study were leaders, from officers to managers. The results this study indicate that there is no significant difference between the performance of kriya tellers (contract employees) and organic tellers (permanent employees) of PT. Bank Syariah Mandiri. Keywords : Performance, Kriya Teller, Organic Teller.
\end{abstract}

\begin{abstract}
ABSTRAK
Penelitian ini berfokus dalam menguji perbedaan kinerja teller kriya (karyawan kontrak) dan teller organik (karyawan tetap) PT Bank Syariah Mandiri. Penelitian ini adalah penelitian komparatif (perbandingan) dengan menggunakan metode kuantitatif. Pengelolaan data dengan menggunakan Mann Whitney. PT Bank Syariah Mandiri sebagai objek dalam penelitian ini. Sampel yang digunakan dalam penelitian adalah pimpinan, mulai dari officer hingga manager. Hasil penelitian ini menunjukkan bahwa tidak adanya perbedaan yang signifikan antara kinerja teller kriya (kayawan kontrak) dengan teller organik (karyawan tetap) PT. Bank Syariah Mandiri.

Kata kunci : Kinerja, Teller Kriya, Teller Organik.

Mila Nurmala Dewi. 2020. Perbandingan Kinerja Teller Kriya Dan Teller Organik PT. Bank Syariah Mandiri. Jurnal Nisbah 6 (2): 75-85

\section{PENDAHULUAN}

Mengelola Sumber Daya Manusia (SDM) menjadi hal yang teramat penting, mengingat SDM merupakan sumber daya utama yang menjadi sentral dan memilki peran dominan untuk menggerakkan roda perkembangan dalam sebuah perusahaan. Faktor Yang paling utama

selain dari pada modal adalah SDM. Maka dari itu, sumber daya manusia sangat diperlukan untuk dikelola dengan baik agar efektivitas dan efisiensi perusahaan semakin meningkat lebih baik (MTE Hariandja, 2002).

Bank syariat bukan hanya memberikan pelayanan dalam pembiayaan saja, namun bank syarah
\end{abstract}


juga memberikan layanan jasa lalu lintas pembayaran. Agar perusahaan mampu bersaing dan tetap bertahan, domminasi teknologi saja tidak cukup jika tidak ditunjang oleh SDM yang handal, sehingga inventasi yang paling berharga adalah sumber daya manusia (Hasibuan, 2003).

Zaman persaingan saat ini, pelayanan bank syariah terhadap nasabah tidak cukup hanya sekedar memuaskan dan sesuai harapan nasabah, akan tetapi harus memberikan pelayanan yang bekesan (LSPP, 2017). Maka prasyarat utama yang harus dibangun adalah manajemen yang berorientasi pada karyawan. Karena dari tangan karyawan inilah layanan pelanggan dibangun dan citra perusahaan diwujudkan (Jhon, 2017).

Celah menggunakan karyawan kontrak terbuka secara umum karena UU ketenagakerjaan mengizinkan hal tersebut, menurut Aloysius Uwiyono (2018) sebagai GB Hukum Perburuhan UI mengungkapkan Undang-Undang memberikan pembatasan masa kontrak kerja, akan tetapi sanksinya tidak tegas dan hal ini terjadi di semua kalangan industri. Adanya karyawan kontrak di Indonesia itu sendiri emang sudah berlangsung cukup lama, baik diterapkan oleh perusahaan lokal atau perusahaan asing, perusahaan swasta maupun perusahaan pemerintah (Ayu, 2010).

PT. Bank Syariah Mandiri (BSM) adalah salah satu bank syariah yang meliki kantor cabang terbanyak yang telah tersebar luas di seluruh Indonesia, berdasarkan data statistic perbankan syariah Otoritas Jasa Keuangan (2019) BSM memiliki 129 kantor cabang utama, 429 kantor cabang serta 55 kantor kas. Maka dari itu BSM membutuhkan karyawan yang cukup banyak untuk melaksanakan kegiatan operasional.

Persaingan dalam dunia bisnis membuat perusahaan harus konsentrasi pada rangkaian pelaksanaan atau kegiatan penciptaan produk dan jasa yang terkait dengan konsep utamanya. Dengan adanya konsentrasi tersebut, akan dihasilkan beberapa produk dan jasa dengan memiliki kualitas dan daya saing di masyarakat. Sistem pengadaan karyawan kontrak pada sebuah perusahaan dapat menghemat biaya dan kewajiaban terhadap karyawan yang bekerja di perusahaan.

Karyawan kontrak dalam peraturan ketenagakerjaan di Indonesia memang diberikan izin dan sudah diatur. Sejatinya kontrak kerja bagi karyawan diberlakukan kepada beberpa pekerjaan pada bagian tertentu. Hal tersebut sesuai dengan Undang-Undang Ketenagakerjaan Nomor 13 Tahun 2003. Karena BSM memilki cabang yang banyak tentunya membutuhkan karyawan yang tidak sedikit, sesuai dengan perjanjian No. 19/368/HCGPPK/KRIYABSM disini Bank Syariah Mandiri juga terdapat program untuk karyawan kontrak pada bagian teller. Perbedaan status karyawan kontrak dan karyawan tetap menjadi persoalan bagi karyawan.

Penelitian ini berfokus pada kinerja teller kriya (karyawan kontrak) dan teller organik (karyawan tetap) BSM. Adanya karyawan kontrak dan karyawan tetap dalam sebuah perusahaan menjadi sebuah fenomena yang menarik untuk dikaji. Terutama dari segi kinerjanya. Hal tersebut membuat penulis tertarik untuk meneliti apakah terdapat perbedaan antara kinerja teller kriya (karyawan kontrak) dengan teller organik (karyawan tetap) pada PT. Bank Syariah Mandiri?

\section{MATERI DAN METODE}

Kinerja adalah mengenai hal yang dilaukan dalam bekerja dan hasil yang diraih dari pekerjaan itu sendiri, kinerja merupakan apa yang dikerjakan dan bagaimana cara melakukannya (Wibowo, 2017). Kinerja secara islami merupakan 
pencapaian dalam sebuah perusahaan dengan berlandaskan pada nilai-nilai syariat atau prinsip-prinsip berdasarkan landasan ekonomi islam (Dian, 2016). Seperti dalam Al-Quran Allah Ta'ala berfirman:

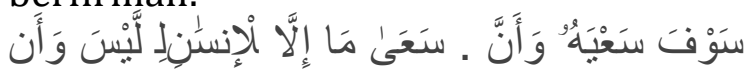

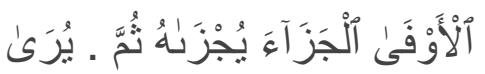

\section{Artinya:}

"Dan bahwasannya (perkara yang sesungguhnya itu ialah) seorang manusia tiada memperoleh selain apa yang telah diusahakannya. Dan bahwasanya usaha itu kelak akan diperlihatkannya (kepadanya). Kemudian akan diberi balasan kepadaanya dengan balasan yang paling sempurna, (QS. An-Najm : 3941)"

Ayat di atas menjelaskan bahwa seseorang manusia tidak mendapatkan pahala kecuali pahala yang ia dapatkan untuk dirinya dengan usahanya sendiri. Usahanya itu akan diperlihatkan di akhirat, lalu kebaikannya dipisakan dengan keburukannya, sebagai pemuliaan bagi orang yang membuat kebajikan dan celaan bagi orang yang membut keburukan. Kemudian manusia diberi balasan atas usahanya dengan balasan yang sempurna untuk semua perbuatannya (Basyir dkk, 2011).

Ketika bekerja dianggap sebagai salah satu ibadah dan bentuk pengabdian kepada umat yang dilakukan Tabel 1. Shared Values ETHIC

\begin{tabular}{|c|c|}
\hline $\begin{array}{c}\text { Shared Values } \\
\text { ETHIC }\end{array}$ & Perilaku Utama \\
\hline $\begin{array}{l}\text { Excellence } \\
\text { Bekerja keras, } \\
\text { cerdas, tuntas, } \\
\text { sepenuh hati untuk } \\
\text { memberikan hasil } \\
\text { yang terbaik. }\end{array}$ & $\begin{array}{l}\text { 1. Antusias, } \\
\text { visioner, } \\
\text { perbaikan } \\
\text { terus } \\
\text { menerus, } \\
\text { bermental } \\
\text { juara. } \\
\text { 2. Disiplin, fokus } \\
\text { dan } \\
\text { berorientasi } \\
\text { pada hasil. }\end{array}$ \\
\hline
\end{tabular}

atas dasar niat karena Allah Ta'ala, maka sumber daya manusia tidak akan mengabaikan adab-adab kerja dalam Islam. Sebaik apapun pekerjaannya, seorang muslim dilarang untuk bersikap sombong atau berbangga diri. Rasulullah bersabda "Tidak masuk surga siapa di dalam hatinya ada kesombongan seberat biji sawi. (HR.Muslim).

Performance sistem biasanya digunakan untuk mengukur tingkat kinerja karyawan dalam perusahaan melalui pengamatan yang dilakukan oleh atasan dari masing-masing unit kerja. Informasi yang didapatkan dari hasil penilaian kinerja tersebut dapat digunakan oleh manajer untuk mengelola kinerja karyawan dan dapat digunakan sebagai pertimbangan untuk menentukan target maupun langkah perbaikan selanjutnya dalam mencapai visi dan misi perusahaan.

Bank Syariah Mandiri (BSM) merumuskan nilai-nilai utama (shared Values) untuk mendorong pencapaian visi dan Misi perusahaan yang disebut BSM Shared Values ETHIC. Nilai tersebut lahir dari kesepakatan seluruh jajaran BSM secara bottom up, agar dapat dipahami dan dilaksanakan oleh seluruh karyawan BSM termasuk pada bagian teller sebagai bagian dari operasianal bank syariah, maka hal tersebut diuraikan dalam 10 perilaku utama sebagai berikut :

\begin{tabular}{|c|c|}
\hline \begin{tabular}{l}
\multicolumn{2}{l}{ Teamwork } \\
Aktif, bersinergi \\
untuk sukses \\
bersama.
\end{tabular} & $\begin{array}{l}\text { 3. Berperan aktif } \\
\text { dan saling } \\
\text { mendukung } \\
\text { untuk } \\
\text { kontribusi } \\
\text { positif. } \\
\text { 4. Membangun } \\
\text { komunikasi } \\
\text { dan kordinasi } \\
\text { yang efektif } \\
\end{array}$ \\
\hline $\begin{array}{l}\text { Humanity } \\
\text { Peduli, ikhlas, } \\
\text { memberi maslahat } \\
\text { dan mengalirkan }\end{array}$ & $\begin{array}{l}\text { 5. Menjadikan } \\
\text { kerja sebagai } \\
\text { ibadah } \\
\text { 6. Memberikan }\end{array}$ \\
\hline
\end{tabular}




\begin{tabular}{|c|c|}
\hline berkah bagi negeri. & $\begin{array}{l}\text { manfaat } \\
\text { kepada Bank } \\
\text { Syariah } \\
\text { Mandiri, } \\
\text { masyarakat } \\
\text { dan } \\
\text { lingkungan. }\end{array}$ \\
\hline $\begin{array}{l}\text { Integrity } \\
\text { Jujur, taat, amanah } \\
\text { dan bertanggung } \\
\text { jawab.. }\end{array}$ & 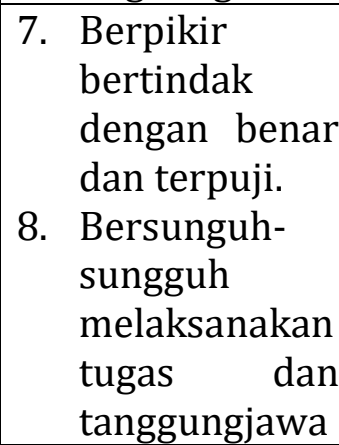 \\
\hline
\end{tabular}

Sumber: Doc. Internal BSM

Tingkat kinerja digunakan sebagai tolok ukur baik atau buruknya kinerja karyawan secara langsung dalam perusahaan. Guna mendapatkan kinerja karyawan yang baik tanpa harus melihat status karyawan (Shafira, 2018). Ukuran-ukuran dari kinerja karyawan menggunakan nilai-nilai utama perusahaan (Shared Values ETHIC) PT. Bank Syariah Mandiri adalah sebagai berikut :
1. Excellence
2. Teamwork
3. Humanity
4. Integrity
5. Customer focus.

Teller merupakan salah satu diantara 3 (tiga) pemeran utama bagi sebuah bank dan memilki peran penting bagi bank, karena frontliner yang memberi kesan langsung kepada nasabah. Sebagai frontliner, teller yang dapat memberikan pelayanan berkesan akan membawa dampak positif bagi bank syariah (LSPP, 2017). Maka dari itu peneliti ingin mengetahui kinerja teller kriya (karyawan kontrak) dan teller organik (teller karyawan) pada PT. Bank Syariah Mandiri.

Teller kriya merupakan teller karyawan kontrak pada PT. Bank

\begin{tabular}{|c|c|}
\hline & $\begin{array}{l}\text { b sesuai } \\
\text { dengan } \\
\text { ketentuan dan } \\
\text { kepatuhan. }\end{array}$ \\
\hline $\begin{array}{l}\text { Customer Focus } \\
\text { Berorientasi } \\
\text { kepada kepuasan } \\
\text { pelanggan yang } \\
\text { berkesinambungan } \\
\text { dan saling } \\
\text { menguntungkan. }\end{array}$ & $\begin{array}{l}\text { 9. Proaktif untuk } \\
\text { memenuhi } \\
\text { kebutuhan } \\
\text { dan kepuasan } \\
\text { pelanggan. } \\
\text { 10. Inovasi } \\
\text { berkelanjutan } \\
\text { untuk } \\
\text { memberikan } \\
\text { solui melebihi } \\
\text { harapan } \\
\text { pelanggan. }\end{array}$ \\
\hline
\end{tabular}

Syariah Mandiri yang diberikan Perjanjian Kerja Waktu Tertentu (PKWT) dengan memiliki jangka waktu hubungan kerja maksimal 2 (dua) tahun. Hal tersebut sesuai dengan Undang - Undang Ketenagakerjaan No. 13 Tahun 2003 serta pada perjanjian program Kriya BSM antara perusahaan PT, Bank Syariah Mandiri dengan peserta pemagangan Kriya BSM.

Teller organik merupakan pegawai yang telah resmi menjadi keryawan tetap perusahaan pada PT. Bank Syariah Mandiri, karyawan dengn bekerja secara total yang tidak terikat oleh kontrak dan jangka waktu bekerja atau masa bekerja (Doc. Internal BSM, 2019).

Berkaitan dengan pentingnya kinerja karyawan dalam menentukan pencapaian tujuan perusahaan, maka berbagai cara dilakukan manajemen untuk meningkatkan mutu karyawan pada bagian teller baik teller kriya maupun teller organik. Untuk itu perlu diterapkan evaluasi kinerja secara konsisten, evaluasi dilakukan untuk mengukur dan mengetahui kinerja teller kriya dan teller organik dengan penilaian yang objektif.

\section{Jenis dan Objek Penelitian}

Penelitian yang dilakukan meggunakan penelitian kuantitatif, interpretasi ini dapat lebih objektif 
apabila alat ukur tersebut diperoleh berdasarkan prosedur yang sistematis serta memilki validitas, reliabilitas dan objektivitas yang cukup tinggi (Azwar, 2004).

Populasi dalam penelitian ini merupakan seluruh teller kriya (karyawan kontrak) dan teller organik (karyawan tetap) serta pimpinan atau atasan mulai dari tingkat officer hingga manager Regional Office Bank Syariah Mandiri. Penelitian ini menggunakan teknik Purposive Sampling. Adapun subjek yang dijadikan sebagai sampel sebanyak 35 pimpinan mulai dari officer hingga manager pada PT. Bank Syariah Mandiri.

Data primer diperoleh dari hasil kuesioner yang telah disebarkan kepada responden, sumber data yang langsung diterima dimana data tersebut harus diolah lagi oleh peneliti. Data sekunder didapat dari skripsi, jurnal, catatan, buku, dan majalah berupa laporan publikasi perusahaan (Wiratna, 2015).

\section{HASIL DAN PEMBAHASAN}

\section{Metode Pengolahan Data}

1. Uji Validitas

Uji validitas dilakukan untuk menguji kuesioner layak digunakan sebagai instrument penelitian. Kriteria dari validitas yaitu apabila nilai $r$ Hitung $>r$ tabel (Ridwan, 2016).

Kriteria dari validitas apabila koefisien kolerasi masing-masing pertanyaan dengan nilai Corrrected Item Total Correlation harus lebih besar $(>0,422)$. Hasil uji validitas menggunakan program SPSS Versi 20 diuraikan dalam tabel berikut :

Tabel di bawah ini menunjukkan seluruh instrumen yang dijadikan sebagai pernyataan untuk mengukur kinerja teller kriya, hasil uji validitas menggunakan program SPSS Versi 22 diuraikan dalam tabel berikut :
Tabel 2. Validitas Kinerja Teller Kriya

\begin{tabular}{|l|c|c|c|}
\hline Pernyataan & $\begin{array}{c}\mathrm{r} \\
\text { Hitung }\end{array}$ & $\begin{array}{c}\mathrm{r} \\
\text { Tabel }\end{array}$ & ket \\
\hline Excellence & 0,756 & 0,422 & Valid \\
\hline 1 & 0,825 & 0,422 & Valid \\
\hline 2 & 0,808 & 0,422 & Valid \\
\hline 3 & 0,745 & 0,422 & Valid \\
\hline 4 & 0,817 & 0,422 & Valid \\
\hline Teamwork \\
\hline 5 & 0,761 & 0,422 & Valid \\
\hline 6 & 0,879 & 0,422 & Valid \\
\hline 7 & 0,909 & 0,422 & Valid \\
\hline 8 & 0,742 & 0,422 & Valid \\
\hline Humanity & 0,872 & 0,422 & Valid \\
\hline 9 & 0,853 & 0,422 & Valid \\
\hline 10 & 0,887 & 0,422 & Valid \\
\hline 11 & 0,879 & 0,422 & Valid \\
\hline 12 & 0,811 & 0,422 & Valid \\
\hline Integrity & 0,870 & 0,422 & Valid \\
\hline 13 & 0,809 & 0,422 & Valid \\
\hline 14 & 0,812 & 0,422 & Valid \\
\hline 15 & 0,804 & 0,422 & Valid \\
\hline 16 & 0,922 & 0,422 & Valid \\
\hline Customer focus \\
\hline 17 & 0,785 & 0,422 & Valid \\
\hline 18 &
\end{tabular}

Sumber: Data diolah, 2019

Tabel 2. Menunjukkan seluruh instrument valid dapat digunakan sebagai pernyataan dalam kuesioner untuk mengukur variabel kinerja teller kriya (karyawan kontrak) yang di teliti pada PT. Bank Syariah Mandiri.

Nilai korelasi tertinggi pada X.19 pada indikator Customer Focus dengan nilai korelasi 0,922, dinyatakan bahwa teller kriya dapat melayani nasabah dengan sepenuh hati dengan mengutamakan kebutuhan nasabah dibandingakan dengan kebutuhan pribadinya.

Teller kriya (karyawan kontrak) dapat menerapkan Shared Values 
ETHIC pada 10 perilaku utama BSM ialah proaktif untuk memenuhi kebutuhan dan kepuasan pelanggan atau nasabah.

Tabel di bawah ini menunjukkan seluruh instrumen yang dijadikan sebagai pernyataan untuk mengukur kinerja teller organik, hasil uji validitas menggunakan program SPSS Versi 22 diuraikan dalam tabel berikut :

Tabel 3. Validitas Kinerja Teller Organik

\begin{tabular}{|l|c|c|c|}
\hline Pernyataan & $\begin{array}{c}\mathrm{r} \\
\text { Hitung }\end{array}$ & $\begin{array}{c}\mathrm{r} \\
\text { Tabel }\end{array}$ & ket \\
\hline Excellence \\
\hline 1 & 0,785 & 0,422 & Valid \\
\hline 2 & 0,752 & 0,422 & Valid \\
\hline 3 & 0,852 & 0,422 & Valid \\
\hline 4 & 0,821 & 0,422 & Valid \\
\hline Teamwork & 0,835 & 0,422 & Valid \\
\hline 5 & 0,875 & 0,422 & Valid \\
\hline 6 & 0,909 & 0,422 & Valid \\
\hline 7 & 0,830 & 0,422 & Valid \\
\hline 8 & 0,776 & 0,422 & Valid \\
\hline Humanity & 0,764 & 0,422 & Valid \\
\hline 9 & 0,851 & 0,422 & Valid \\
\hline 10 & 0,895 & 0,422 & Valid \\
\hline 11 & 0,890 & 0,422 & Valid \\
\hline 12 & 0.762 & 0,422 & Valid \\
\hline Integrity & 0,870 & 0,422 & Valid \\
\hline 13 & 0,706 & 0,422 & Valid \\
\hline 14 & 0,894 & 0,422 & Valid \\
\hline 15 & 0,865 & 0,422 & Valid \\
\hline 16 & 0,851 & 0,422 & Valid \\
\hline Customer focus & 0,869 & 0,422 & Valid \\
\hline 17 & 0
\end{tabular}

Sumber : Data diolah, 2019

Tabel 3. Menunjukkan seluruh instrumen valid untuk digunakan sebagai pernyataan dalam mengukur kinerja teller organik (karyawan tetap) yang diteliti pada PT. Bank Syariah Mandiri.
Nilai korelasi tertinggi pada X.7 pada indikator teamwork dengan nilai korelasi 0,909, dinyatakan bahwa teller organik memilki komunikasi dan kordinasi yang baik antar rekan kerja.

Sesuai dengan Shared Values ETHIC pada 10 perilaku utama BSM, teller organik (karyawan tetap) dapat membangun komunikasi dan kordinasi yang efektif.

2. Uji Reliabilitas

Uji reliabilitas adalah ukuran suatu kestabilan dan konsistensi responden dalam menjawab pernyataan dalam kuesioner yang tekah disebaran, dari masingmasing instrumen menggunakan Cronbach's Alpha.

Kuesioner reliabel apabila nilai koefisien Alpha lebih besar dari 0,6 (a $>0,6)$. Berikut adalah hasil uji reliabilitas menggunakan program SPSS 22 diuraikan dalam tabel berikut:

Tabel 4. Reliabilitas Kinerja Teller kriya

Reliability Statistics

\begin{tabular}{|r|r|}
\hline $\begin{array}{c}\text { Cronbach's } \\
\text { Alpha }\end{array}$ & $\begin{array}{c}\text { N of } \\
\text { Items }\end{array}$ \\
\hline .974 & 20 \\
\hline
\end{tabular}

Tabel 4. di atas memiliki nilai Cronbach's Alpha sebesar 0,974 atau dapat dikatakan lebih besar dari 0,6 $(0,974>0,6)$, maka instrumen dinyatakan reliabel. 
Tabel 5. Reliabilitas Kinerja Teller Organik

Reliability Statistics

\begin{tabular}{|r|r|}
\hline $\begin{array}{c}\text { Cronbach's } \\
\text { Alpha }\end{array}$ & $\begin{array}{c}\text { N of } \\
\text { Items }\end{array}$ \\
\hline .976 & 20 \\
\hline
\end{tabular}

Tabel 5. di atas memilki nilai Croncbach's Alpha sebesar 0,976 atau dapat dikatakan lebih besar dari $0,6 \quad(0,976>0,6)$, maka instrument dinyatakan reliabel.

\section{Teknik Analisis Data}

\section{Skala Likert}

Skala likert adalah tahapan yang menjabarkan hasil dari kuesioner yang diisi oleh responden mengenai variabel kinerja, baik teller kriya maupun teller organik.

Indikator yang digunakan dalam variabel kinerja berjumlah 5 indikator, dapat dilihat keteragan sebagai berikut :
X.1 - X.4
Excellence
X.4 - X.8
Teamwork
$\mathrm{X} .9-\mathrm{X} 12$
Humanity
X.13 - X.16 Integrity
X.17 - X.20 Customer Focus

Tabel 6. Skala Likert Kinerja Teller Kriya

Descriptive Statistics

\begin{tabular}{|l|r|r|r|}
\hline & Mean & $\begin{array}{c}\text { Std. } \\
\text { Deviation }\end{array}$ & \multicolumn{1}{c|}{$\mathrm{N}$} \\
\hline $\mathrm{X} .1$ & 3.60 & .553 & 35 \\
$\mathrm{X} .2$ & 3.46 & .561 & 35 \\
$\mathrm{X} .3$ & 3.49 & .562 & 35 \\
$\mathrm{X} .4$ & 3.60 & .553 & 35 \\
$\mathrm{X} .5$ & 3.63 & .490 & 35 \\
$\mathrm{X} .6$ & 3.60 & .695 & 35 \\
$\mathrm{X} .7$ & 3.60 & .497 & 35 \\
$\mathrm{X} .8$ & 3.46 & .561 & 35 \\
$\mathrm{X} .9$ & 3.57 & .502 & 35 \\
$\mathrm{X} .10$ & 3.46 & .657 & 35 \\
$\mathrm{X} .11$ & 3.46 & .561 & 35 \\
$\mathrm{X} .12$ & 3.57 & .502 & 35 \\
$\mathrm{X} .13$ & 3.54 & .505 & 35
\end{tabular}

\begin{tabular}{|l|l|l|l|} 
X.14 & 3.57 & .502 & 35 \\
X.15 & 3.60 & .553 & 35 \\
X.16 & 3.46 & .657 & 35 \\
X.17 & 3.40 & .695 & 35 \\
X.18 & 3.46 & .657 & 35 \\
X.19 & 3.54 & .505 & 35 \\
X.20 & 3.54 & .505 & 35 \\
\hline
\end{tabular}

Berdasarkan Tabel 6. kuesioner yang telah dibagikan kepada Officer dan Manager PT Bank Syariah Mandiri, memperoleh hasil perhitungan Skala Likert dengan angka kriteria penafsiran pada jawaban sangat setuju berada di angka angka Mean 3,25 - 4,00 dari 20 pernyataan. Dapat dinyatakan responden Officer atau Manager dominan memilih jawaban "Sangat Setuju" pada pernyataan yang diberikan dalam menilai teller kriya. Tabel 7. Skala Likert Kinerja Teller Organik

Descriptive Statistics

\begin{tabular}{|l|r|r|r|}
\hline & \multicolumn{1}{|c|}{ Mean } & $\begin{array}{c}\text { Std. } \\
\text { Deviation }\end{array}$ & \multicolumn{1}{c|}{$\mathrm{N}$} \\
\hline X.1 & 3.54 & .561 & 35 \\
X.2 & 3.63 & .547 & 35 \\
X.3 & 3.49 & .562 & 35 \\
X.4 & 3.43 & .655 & 35 \\
X.5 & 3.49 & .562 & 35 \\
X.6 & 3.60 & .553 & 35 \\
X.7 & 3.60 & .497 & 35 \\
X.8 & 3.49 & .658 & 35 \\
X.9 & 3.57 & .502 & 35 \\
X.10 & 3.51 & .507 & 35 \\
X.11 & 3.34 & .639 & 35 \\
X.12 & 3.40 & .553 & 35 \\
X.13 & 3.60 & .497 & 35 \\
X.14 & 3.69 & .471 & 35 \\
X.15 & 3.54 & .505 & 35 \\
X.16 & 3.57 & .502 & 35 \\
X.17 & 3.51 & .562 & 35
\end{tabular}




\begin{tabular}{|l|l|l|l|} 
X.18 & 3.54 & .657 & 35 \\
X.19 & 3.60 & .497 & 35 \\
X.20 & 3.49 & .507 & 35 \\
\hline
\end{tabular}

Berdasarkan Tabel 7. Pada variabel kinerja teller organik diketahui terdapat 20 pernyataan (x.1-x.2). indikator yang digunakan dalam variabel kinerja berjumlah 5 indikator dimana masing-masing indikator memilki 4 pernyataan.

Berdasarkan kuesioner yang telah dibagikan kepada Officer dan Manager PT Bank Syariah Mandiri, memperoleh hasil perhitungan Skala Likert dengan angka kriteria penafsiran untuk jawaban sangat setuju pada angka Mean 3,25 - ,00 memilki perolehan dengan jumlah 20 pernyataan, dapa dinyatakan responden Officer dan Manager dominan memilih jawaban "Sangat Setuju" pada pernyataan yang diberikan dalam menilai kinerja teller oganik.

2. Mann Whitney

Uji Mann Whitney digunakan untuk menganalisis signifikan perbedaan antara dua sampel yang independent. Penelitian ini menggunakan uji non parametrik karena datanya tidak terdistribusi secara normal dapat dilihat dari 35 jawaban responden officer dan Manager.

Hipotesis penelitian :

$\mathrm{H}_{0}$ : Tidak terdapat perbedaan kinerja antara teller kriya (karyawan kontrak) dengan teller organik (karyawan tetap).

$\mathrm{H}_{\mathrm{a}}$ : Terdapat perbedaan kinerja teller kriya (karyawan kontrak) dengan teller organik (karyawan tetap)

Dasar pengambilan keputusan menggunakan perbandingan antara nilai signifikasi. Jika nilai Sig. $<0,05$ maka dapat disimpulkan bahwa perbedaannya signifikan dan berarti $\mathrm{H}_{\mathrm{o}}$ ditolak dan $\mathrm{H}_{\mathrm{a}}$ diterima. Sedangkan jika nilai Sig. > 0,05 maka tidak adanya perbedaan dan brarti $\mathrm{H}_{0}$ diterima dan $\mathrm{H}_{\mathrm{a}}$ ditolak.

Perhitungan Uji Mann Whitney menggunakan bantuan program SPSS Versi 22, sehingga didapatkan hasil pada tabel sebagai berikut :

Tabel 8. Rank Kinerja

\begin{tabular}{|c|c|c|c|c|}
\hline & teller & $\mathrm{N}$ & $\begin{array}{l}\text { Mean } \\
\text { Rank }\end{array}$ & $\begin{array}{c}\text { Sum } \\
\text { of } \\
\text { Ranks }\end{array}$ \\
\hline \multirow[t]{4}{*}{$\begin{array}{l}\text { kiner } \\
\text { ja }\end{array}$} & $\begin{array}{l}\text { teller } \\
\text { kriya }\end{array}$ & 35 & $\begin{array}{r}35.3 \\
7\end{array}$ & $\begin{array}{r}1238 . \\
00\end{array}$ \\
\hline & teller & 35 & 35.6 & 1247. \\
\hline & organi & & 3 & 00 \\
\hline & Total & 70 & & \\
\hline
\end{tabular}

Tabel 8. Menunjukkan $\mathrm{N}$ atau keseluruhan sampel Officer dan Manager sebanyak 35 responden menilai kinerja teller kriya dan teller organik dengan teller kriya Mean Rank sebesar 35,37 dan Sum of Rank sebesar 1238,00, sedangkan teller organik Mean Rank sebesar 35,63 dan Sum of Rank sebesar 1247,00 .

Nilai Sum of Rank didapat dari Mean Rank x N, data tersebut menunjukkan bahwa Mean Rank dan Sum of Rank kinerja teller kriya lebih rendah dibandingkan dengan kinerja teller organik. Hal tersebut dapat dilihat dari nilai mean rank teller kriya yaitu 35,37 sedikit lebih rendah daripada mean rank teller organik yang memiliki nilai 35,63.

Pengaruh terhadap nilai signifikannya dapat dilihat dalam uji Mann Whitney dengan SPSS Versi 22 sebagai berikut: 
Tabel 9. Uji Mann Whitney

Test Statistics ${ }^{\mathrm{a}}$

\begin{tabular}{|l|r|}
\hline & \multicolumn{1}{|c|}{ Kinerja } \\
\hline Mann-Whitney U & 608.000 \\
Wilcoxon W & 1238.000 \\
Z & -.054 \\
Asymp. Sig. (2- & .957 \\
tailed)
\end{tabular}

a. Grouping Variable: teller

Tabel 9. Merupakan Output Test Statistic dala Uji Mann Whitney diketahui bahwa nilai U sebesar 608,000 dan nilai $W$ sebesar 1238,000. Apabila dikonversikan ke nilai $\mathrm{Z}$ maka besarnya $-0,054$, nilai Asymp. Sig. (2-tailed) sebesar 0,957 $>0,05$. Artinya $\mathrm{H}_{0}$ diterima dan $\mathrm{H}_{\mathrm{a}}$ ditolak.

Disimpulkan bahwa tidak terdapat perbedaan kinerja yang signifikan antara teller kriya (karyawan kontrak) dengan teller organik (karyawan tetap). Berdasarkan data statistik didapatkan bahwa kinerja teller kriya dan teller organik tidak memiliki perbedaan hanya ada perbedaan nilainya yang sedikit rendah.

Davis dalam Mangkunegara (2005) berpendapat bahwa kinerja karyawan merupakan perpaduan dan kemampuan serta motivasi yang dimiliki oleh setiap masingmasing dari karyawan itu sendiri.

Faktor kemampuan terdiri dari kemampuan intelektual dan kemampuan fisik. Pada kemapuan intelektual setiap karyawan dituntut untuk memiliki kecerdasan numeric, pemahaman verbal, kecepatan perceptual dan ingatan yang baik.

Faktor motivasi terdiri dari kebutuhan eksistensi, kebutuhan keterkaitan dan kebutuhan pertumbuhan. Hal ini mempengaruhi terjadinya perbedaan pada kinerja seseorang dalam perusahaan.

Penelitian terdahulu yang dilakukan oleh Ayu (2014) memberikan hasil penelitian bahwa kinerja karyawan tetap lebih tinggi dibandingkan kinerja karyawan kontrak, hal tersebut disebabkan karena perbedaan perolehan insentif. Dapat kita ketahui bahwa karyawan tetap memperoleh insentif yang lebih tinggi dibandingkan dengan karyawan kontrak.

Hal tersebut didukung oleh penelitian ini, meskipun kinerja teller organik (karyawan tetap) dan teller kriya (karyawan kontrak) memiliki perbandingan yang tidak signifikan. Namun kinerja teller organik (karyawan tetap) tetap lebih tinggi dibandingkan dengan teller kriya (karyawan kontrak).

Tuntutan persaingan antar karyawan yang semakin tinggi, membuat teller kriya dan teller organik berusaha meningkatkan kemampuan kinerjanya, dimana teller kriya bekerja semaksimal mungkin untuk melakukan pekerjaan dengan baik agar mereka dapat diangkat menjadi karyawan tetap. Sebaliknya dengan teller organik bekerja semaksimal mungkin melakukan pekerjaannya agar mereka dapat serius dalam jenjang karir untuk kenaikan jabatannya (Nurhikmah, 2017).

\section{KESIMPULAN DAN IMPLIKASI}

Hasil yang telah ditetapkan pada penelitian ini dapat dijabarkan bahwa tidak adanya perbedaan yang signifikan pada kinerja teller kriya (karyawan kontrak) dan teller organik (karyawan tetap) PT. Bank Syariah Mandiri.

Keduanya memiliki tujuan bersamasama dalam bekerja sehingga memberikan dampak yang baik 
terhadap perkembangan perusahaan (wahyuningtyas, 2018). Hal ini menunjukkan bahwa komitmen PT. Bank Syariah Mandiri sangat baik karena berhasil berkembang bersama dengan karyawan-karyawannya.

Variabel kinerja karyawan memiliki perbedaan yang tidak signifikan pada kelompok teller kriya (karyawan kontrak) dengan teller organik (karyawan tetap) sehingga perusahaan lebih baik memberikan prioritas yang sama dalam setiap kebijakan yang diberikan kepada karyawan.

Penelitian ini dilakukan dengan jumlah sampel yang sedikit, sehingga peneliti berharap penelitian ini dapat dilakukan dalam jumlah sampel yang lebih banyak guna melihat keakuratan data dan fakta.

\section{DAFTAR PUSTAKA}

Firdausi, Ayu Rahmania. 2014. Analisis Perbedaan Kinerja antara Karyawan Tetap dan Karyawan Kontrak (Studi pada PT. Lapimak Primula Indonesia). Universitas Jember

Gunawan. 2004. Pengantar Statistik. Bandung : Bumi Aksara.

Handoko. 2002. MSDM dan Job Satisfaction. Bandung : PT. Permata.

Hasibuan S.P. Malayu. Manajemen Sumber Daya Manusia Cetakan Kesembilan. Jakarta: Bumi aksara.

Hasibuan. 2002. MSDM Konsep, Teori dan Pengembangan dalam Konteks Organisasi Publik. Yogyakarta : Graha Ilmu.

Lestari, Dwi. 2006. Faktor-Faktor yang Mempengaruhi Semangat Kerja karyawan Tetap dan Karyawan Kontrak
Mangkunegara 2005. Peningkatan Produktivitas Karyawan dan prinsip - prinsip memotivasi karyawan. Jakarta : Pustaka.

Mangkunegara, Anwar Prabu. 2006. Evaluasi Kinerja SDM. Jakara: Eresco.

Purnama, dkk. 2015. Analisis Perbandingan Prestasi Kerja Karyawan Kontrak dengan Karyawan Tetap. Jurnal Administrasi Bisnis (JAB) Vol. 26 No. 1.

Putri, Nurhikmah. 2017. Analisis Perbandingan Kinerja Karyawan Tetap dengan Karyawan Outsourcing (Kontrak) (Studi Kasus pada Plasa Telkom Regional 7 Cabang Makassar).

Rahmania, Firdausi. 2014. Analisis Perbedaan Kinerja Antara Karyawan Tetap dan Karyawan kontrak Pada PT. Lamipak Primula Indonesia.

Robbins, Stephen P. 1998. Organizational Behavior. USA : Prentice Hall.

Robin. 2008, Prinsip - Prinsip Motivation. Jakarta : PT. Jaya.

Sugiyono. 2006. Metode Penelitian Bisnis. Bandung: Alfabeta.

Sugiyono. 2014. Metode Penelitian Kuantitatif, Kualitatif, Kombinasi (Mixed Methods), Bandung : Alf abeta.

Wahyuningtyas dan Hamidah. 2018. Jurnal Administrasi Bisnis. Vol. 60 No. 3. 
Wibowo. 2007. Manajemen Kinerja

(Edisi Kelima). Jakarta: Raja Grafindo Pers.

Wijayanti, Ratna. 2010. Pengaruh Kepemimpinan, Motivasi, dan Komitmen Organisasi Terhadap Kinerja PNS Dilingkungan Organisasi Dinas Pendidikan Kabupaten Kudus. Vol. 4 No.

Buku Panduan Lembaga Sertifikasi Profesi Perbankan 2017.

Buku Panduan Pemagangan Kriya BSM 2017.

Doc. Bank Syariah Mandiri KCP Citeureup.

Undang Undang Tenaga Kerja No.13 Tahun 2000.

http://ekonomi-islam.com

http://syariah.mandiri.co.id

http://www.ir-bri.com 